\title{
PHYTOCHEMICAL COMPOSITION AND BIOLOGICAL ACTIVITIES OF CRUDE EXTRACT FROM FLOWERS AND LEAVES OF Rhododendron arboreum Sm. FROM NORTHERN THAILAND
}

\author{
SUPANIDA WINITCHAI ${ }^{1}$, SIRILUCK LIENGPRAYOON ${ }^{1}$, WARAWUT SUPHAMITMONGKOL ${ }^{1}$, \\ NADDAMAS TOMORN ${ }^{1}$, JATUPORN CHAIYUT ${ }^{1}$, TUKSIN LERKSAMRAN ${ }^{1}$, YUTTHANA BANCHONG ${ }^{1}$, \\ PIYAPAT TRISONTHI ${ }^{2}$, SAFIAH SAAH ${ }^{2}$ and NATEDAO MUSIGAMART ${ }^{1 *}$ \\ ${ }^{1}$ Kasetsart Agricultural and Agro-Industrial Product Improvement Institute (KAPI), \\ Kasetsart University, Bangkok 10900, Thailand \\ ${ }^{2}$ Institute of Food Research and Product Development (IFRPD), \\ Kasetsart University, Bangkok 10900, Thailand \\ *E-mail: aapndm@ku.ac.th
}

Accepted 10 July 2021, Published online 31 December 2021

\begin{abstract}
Rhododendron arboreum $\mathrm{Sm}$. has wide applications in food and beverage, medicines, and cosmetics because the plant contains bioactive phytochemical components. In Thailand, other than for horticultural purposes, scant literature describes the potential applications of this Rhododendron species. Phytochemical composition, biological activity, and cell cytotoxicity of $R$. arboreum Sm. flower petal and leaf extracts were determined. Ethanolic extracts of fresh and dried flower petals (FF and DF, respectively) and dried leaves (DL) of $R$. arboreum were prepared by maceration with $60 \%$ ethanol for 7 days. Extraction yields of both FF and DF were higher than DL (19.22, 16.76, and 8.50\% for FF, DF, and DL, respectively). Preliminary qualitative phytochemical screening showed different compositions in diverse plant parts. Saponins and tannins were present in every extract, with anthraquinones detected only in flowers and terpenoids only in leaves. Total phenolic (TPC) and flavonoid contents (TFC) were highest in DL (405.21 mg gallic acid equivalent and $127.30 \mathrm{mg}$ catechin equivalent per g of dry extract, respectively), followed by DF and FF. Antioxidant properties were determined using two radical scavenging assays as 2,2-diphenyl-1-picrylhydrazyl (DPPH) and 2,2-azinobis(3-ethyl-benzthiazoline-6-sulfonic acid (ABTS). Results indicated that all extracts exhibited better inhibitory activity against DPPH radical than ABTS radical as evidenced by lower $\mathrm{IC}_{50}$ range $24.65-48.15 \mathrm{ig} / \mathrm{mL}$ for $\mathrm{DPPH}$ and $65.19-76.36 \mathrm{ig} / \mathrm{mL}$ for ABTS, respectively. A positive correlation coefficient between the two antioxidant assays and TPC and TFC of Rhododendron extracts indicated antioxidant potential distributed in both components. No cytotoxicity was recorded in the three extracts, with concentrations less than $500 \mu \mathrm{g} /$ $\mathrm{mL}$ for both 3-(4,5-dimethylthiazol-2yl)-2,5-diphenyltetrazolium bromide (MTT) and CellTiter-Blue ${ }^{\circledR}$ assay. In vitro studies exhibited dose-dependent and strong anti-melanogenic and anti-inflammatory activities ranging from 50 to $250 \mu \mathrm{g} / \mathrm{mL}$ for FF, DF, and DL. Results identified various bioactive constituents with potential biological activity (antioxidant, antiinflammatory, and anti-melanogenic), while non-cytotoxicity in $R$. arboreum flower and leaf extracts suggested the possibility of further applications as a functional ingredient in cosmetics.
\end{abstract}

Key words: Anti-inflammatory, anti-melanogenic, antioxidant, cytotoxicity, Rhododendron arboreum Sm.

\section{INTRODUCTION}

The number of plant species used in cosmetic and healthcare products has increased in recent years owing to consumer preference for natural products with few harmful side effects that are not chemically synthesized (Aburjai \& Natsheh, 2013; Joshi \& Pawar, 2015; Gonzalez-Minero \& Bravo-Díaz, 2018).

* To whom correspondence should be addressed.
Rhododendron arboreum Sm., a member of genus rhododendron, is recognized for its impressive flowers with different color shades. Rhododendron plant parts are also used in traditional medicine to treat diabetes, arthritis, headache, gout, musculoskeletal diseases, and hypertension in India, Nepal, Tibet, and China, where Rhododendron species originated (Sharma et al., 2010; Srivastava, 2012; Sonar et al., 2012; Popescu \& Kopp, 2013). 
Rhododenron arboreum extracts have high antioxidant potential such as anti-aging, antiinflammatory, anti-tyrosinase, hypolipidemic, UV protection, and moisturizing properties when used in cosmetic products (Swamidasan et al., 2008; Tigari et al., 2008; Verma et al., 2011; Thangaraj, 2013; Kim et al., 2016). These bioactive properties are involved with various components such as flavonoids, tannins, essential oils, chromones (isomers of coumarins), terpenoids, and steroids (Krishna et al., 2014). Flavonoids comprise the majority of phytochemicals found in rhododendron species, including $R$. arboreum. Among these chemicals, quercetin and its derivatives are important bioactive flavonoid compounds with remarkable antioxidant potential. They are also effective in the suppression of inflammation and melanogenesis (Qiang et al., 2011; Choi \& Shin, 2016). Quercitrin and rutin are the main flavonoid derivatives abundant in flowers of $R$. arboretum (Srivastava, 2012; Kumar et al., 2019). In previous studies, these compounds are strong antiinflammatory and anti-melanogenesis agents. Quercitrin extracted from Lindera obtusiloba Blume decreases the melanin content in B16F10 melanoma cells by causing downregulation of MITF and tyrosinase protein transcription, and it is a stronger inhibitor than kojic acid, which is a well-known tyrosinase inhibitor (Hong et al., 2013). Rutin, in combination with ascorbic acid, is effective in the protection of human skin keratinocytes from UVAand UVB-induced oxidative stress through its combined bioactivities, which include antioxidant, anti-inflammation, and anti-apoptotic activities (Gêgotek et al., 2019). Furthermore, rhododendron species also comprise several phenolic acids; namely, coumaric acid, chlorogenic acid, and ferulic acid. Most of these are good sources of antioxidant activity (Qiang et al., 2011). Considering this phytochemical perspective, $R$. arboreum extract has good potential for application in the cosmetic industry.

The genus Rhododendron is widely distributed except for South and Central America and Africa. It is comprised of more than 1,000 species over the world (Demir et al., 2016). Studies have shown that environmental conditions (such as growth area, temperature, sunlight, precipitation, and humidity) are factors affecting the metabolism of plant secondary metabolites and contribute to their different active ingredients and biological activities (Dong et al., 2011; Liu et al., 2015). Previous studies have demonstrated that alcoholic $R$. arboreum extracts from various growth locations produce diverse phenolic and flavonoid contents, resulting in differences in their antioxidant power. The highest total phenolic content (TPC) of $R$. arboreum leaf and flower extracts from Nepal (Bhandari \& Rajbhandari,
2015) ranged from 495.0 to $440.0 \mathrm{mg} \mathrm{GAE} / \mathrm{g}$ extract, while lower TPC values of $R$. arboreum extract from Himachal Pradesh (Sharma et al., 2021) and Uttarakhand Region of India (Painuli et al., 2018; Lubhan, 2016) were reported ranging from 339.2 to $9.7 \mathrm{mg} \mathrm{GAE} / \mathrm{g}$ extract. The highest total flavonoid content (TFC) at $651.0 \mathrm{mg} / \mathrm{g}$ RE per gram extract was reported from the Uttarakhand Region of India (Painuli et al., 2018), followed by the Himachal Pradesh area and Nepal at 254.3 to 115.1 and 150.0 to $103.8 \mathrm{mg} / \mathrm{g}$ RE per gram extract, respectively (Bhandari \& Rajbhandari, 2015; Sharma et. al., 2021), while the lowest TFC value was observed by Lubhan (2016) from the Uttarakhand Region at 25.8 to 23.2 $\mathrm{mg} / \mathrm{g}$ RE per gram extract. In terms of antioxidant determination using 2,2-Diphenyl-1-picrylhydrazyl (DPPH) assay, a similar trend to the TPC results was observed. A low $\mathrm{IC}_{50}$, indicating high antioxidant activity was reported by Bhandari \& Rajbhandari (2015), ranging from 8.34 to $25.15 \mu \mathrm{g} / \mathrm{mL}$, while the low antioxidant activity of all $R$. arboreum extracts from India was reported by Painuli et al. (2018), Sharma et al. (2021) and Lubhan (2016) with $\mathrm{IC}_{50}$ values ranging from 91.67 to $477.97 \mu \mathrm{g} / \mathrm{mL}$.

In Thailand, only 11 species of Rhododendron including $R$. arboreum grow naturally at a high altitude of 2000 to 2400 meters above sea level around Doi Chiang Dao and Doi Inthanon, Thailand's highest mountains. The flowering season is from November to February. Copious research on the bioactive components presented in $R$. arboreum and their characterization in terms of chemical nature and biological activities have previously been conducted. However, aside from horticultural purposes, no attempt has been made to exploit other potential applications of this plant species in Thailand. Accordingly, here, we investigated the phytochemicals obtained from $R$. arboreum $\mathrm{Sm}$. flower and leaf extracts, as well as cell toxicity and biological activities to evaluate their potential for further higher-value applications such as natural ingredients for cosmetic and healthcare products.

\section{MATERIALS AND METHODS}

\section{Plant samples}

Rhododendron arboreum Sm. samples were kindly provided by the Rhododendron Collecting Plantation of Inthanon Royal Agricultural Station, Chiang Mai, Thailand. All samples were collected during February 2018. The plant was taxonomically identified using the Flora of Thailand (Santisuk \& Balslev, 2015) and compared with specimens no. QBG 103698 deposited in the Queen Sirikit Botanic Garden Herbarium, the Botanical Garden Organization, Chiang Mai, Thailand. Our voucher specimens no. KAPI- 
2018-001 were kept at Kasetsart Agricultural and Agro-Industrial Product Improvement Institute (KAPI), Kasetsart University, Bangkok, Thailand.

\section{Extraction method}

Three types of samples were used: fresh flower petals (FF), dried flower petals (DF), and dried leaves (DL). Ethanolic of Rhododendron extracts were produced as described previously by $\mathrm{Ng}$ et al. (2020a; 2020b) with modification. Drying of flower petals and leaves was performed at $40^{\circ} \mathrm{C}$ for $48 \mathrm{hr}$ in a ventilated oven. After drying, the samples were ground into a fine powder using a blender. Each sample was extracted by maceration in $60 \%$ ethanol at the ratio of 1:30 (sample: solvent, w/v) for 7 days at room temperature $\left(25^{\circ} \mathrm{C}\right)$ with $1 \mathrm{hr}$ daily agitation. The extracts were then filtrated through filter paper (Whatman No. 1), and the filtrate was evaporated to dryness by a rotary evaporator. Extractions were performed as three replicates, and the extraction yield was calculated on a dry weight basis. All extract samples were kept at $4{ }^{\circ} \mathrm{C}$ for further analysis.

\section{Phytochemical screening}

All of $R$. arboreum extracts were chemically screened for seven groups of secondary metabolites, following the methods described by Ayoola et al. (2008).

\section{Alkaloids}

An aliquot of $0.2 \mathrm{~g}$ of sample was weighed and mixed with $15 \mathrm{~mL}$ of $10 \%$ sulfuric acid $\left(\mathrm{H}_{2} \mathrm{SO}_{4}\right)$. The mixture was warmed for $5 \mathrm{~min}$ in a water bath. After filtration, five drops of Dragendorff's reagent were added to the sample. The presence of alkaloids was proved by an orange-red precipitate.

\section{Flavonoids}

About $0.2 \mathrm{~g}$ of sample was dissolved in $3 \mathrm{~mL}$ of $50 \%$ ethanol and filtered to remove the insoluble residue. A piece of magnesium wire was placed in the solution. Five drops of concentrated hydrochloric acid $(\mathrm{HCl})$ were added to the mixture and warmed in a water bath for $5 \mathrm{~min}$. The yellow color of the solution indicated the presence of flavonoids.

\section{Anthraquinones}

The sample $(0.2 \mathrm{~g})$ was mixed with $10 \mathrm{~mL}$ of $10 \%$ $\mathrm{H}_{2} \mathrm{SO}_{4}$. The mixture was warmed for $5 \mathrm{~min}$ and then filtered. Ten milliliters of $10 \%$ ammonia $\left(\mathrm{NH}_{3}\right)$ solution were added and mixed well. A pink color indicated the presence of anthraquinones.

\section{Saponins}

Five milliliters of water were mixed with $0.2 \mathrm{~g}$ of sample and warmed in a water bath for $5 \mathrm{~min}$ before vigorously shaken. Frothing indicated the presence of saponins.

\section{Cardiac glycosides}

A $0.2 \mathrm{~g}$ sample was dissolved in $1 \mathrm{~mL}$ of chloroform and filtered to remove the insoluble residue. The filtrate was mixed with 5 drops of $1 \%$ ferric chloride $\left(\mathrm{FeCl}_{3}\right)$ before adding 5 drops of glacial acetic acid. Then, $0.5 \mathrm{~mL}$ of concentrated $\mathrm{H}_{2} \mathrm{SO}_{4}$ was gradually added, and the appearance of a brown ring between the interface of acid and sample solution showed the presence of cardiac glycoside.

\section{Tannins}

About $0.2 \mathrm{~g}$ of the sample was mixed with $5 \mathrm{~mL}$ of distilled water and warmed in a water bath for 5 min. The filtered solution was mixed with 5 drops of $1 \% \mathrm{FeCl}_{3}$. The presence of tannins was confirmed if the solution turned dark green or blue-green.

\section{Terpenoids}

A sample of $0.2 \mathrm{~g}$ was dissolved in $1 \mathrm{~mL}$ of chloroform and filtered to remove the insoluble residue. Then, $0.5 \mathrm{~mL}$ of concentrated $\mathrm{H}_{2} \mathrm{SO}_{4}$ was gradually added. A brown ring appearing at the interface indicated the presence of terpenoids.

\section{Total flavonoid content (TFC) quantification}

The total flavonoid content of rhododendron extract was determined based on the work of Younus et al. (2021). The $250 \mu \mathrm{L}$ of rhododendron extract was mixed with $75 \mu \mathrm{L}$ of $5 \%$ sodium nitrite $\left(\mathrm{NaNO}_{2}\right)$ and $1.25 \mathrm{~mL}$ of distilled water. After incubated for $5 \mathrm{~min}$ at $25^{\circ} \mathrm{C}, 150 \mu \mathrm{L}$ of $10 \%$ aluminum chloride $\left(\mathrm{AlCl}_{3}\right)$ was added. The solution was incubated for 6 min, and then well-mixed with $500 \mu \mathrm{L}$ of $1 \mathrm{M}$ sodium hydroxide $(\mathrm{NaOH})$ and $275 \mu \mathrm{L}$ of distilled water. A standard calibration was performed using catechin (30-300 $\mu \mathrm{g} /$ $\mathrm{mL}$ concentration) and distilled water was used as the blank. The absorbance was measured at $510 \mathrm{~nm}$ using a spectrophotometer (Bio-Tek Instruments, Inc., Winooski, VT, USA). Triplicate measurements were performed. Total flavonoid content was expressed in milligrams of catechin equivalent ( $\mathrm{mg}$ CE) per gram of dry extract.

\section{Total phenolic content (TPC) determination}

Total phenolic content was quantified following by Ainsworth \& Gillespie (2007). Briefly, $0.5 \mathrm{~mL}$ of distilled water and $125 \mu \mathrm{L}$ of rhododendron extract or the standard were mixed into the test tubes. FC reagent $(125 \mu \mathrm{L})$ was added to the solution and incubated for $6 \mathrm{~min}$ to allow the reaction. Then, 1.25 $\mathrm{mL}$ of $7 \%$ sodium carbonate in distilled water and 1 $\mathrm{mL}$ of distilled water were added to the test tubes. Each test tube was shaken and allowed to stand for $90 \mathrm{~min}$ at room temperature $\left(25^{\circ} \mathrm{C}\right)$ to complete the reaction. The absorbance was measured using a spectrophotometer (UV-1800, Shimadzu, Japan) at 760 $\mathrm{nm}$. Triplicate measurements were performed for comparison with the standard value; gallic acid 
solution at $0-100 \mu \mathrm{g} / \mathrm{mL}$ concentrations. TPC was expressed as a unit of milligrams of gallic acid equivalent (mg GAE) per gram of dry extract.

\section{2,2-Diphenyl-1-picrylhydrazyl (DPPH) radical scavenging assay}

Antioxidant activities of rhododendron extracts were determined using 2,2-Diphenyl-1-picrylhydrazyl (DPPH) assay as described by Mankil et al. (2006). A $100 \mu \mathrm{L}$ aliquot of rhododendron extract at various concentrations was added to $96-$ well plates containing $50 \mu \mathrm{L}$ of $0.5 \mathrm{mg} / \mathrm{mL}$ concentration of ethanolic DPPH solution. Ascorbic acid (SigmaAldrich, USA) was used as a standard. The decrease of absorbance at $515 \mathrm{~nm}$ was monitored after $30 \mathrm{~min}$. Antioxidant activity was calculated by the following equation:

$\%$ DPPH radical scavenging activity $=\frac{\mathrm{A}-\mathrm{B}}{\mathrm{A}} \times 100$

Where A is DPPH absorbance and B is the absorbance after sample addition.

\section{2,2'-azino-bis(3-ethylbenzthiazoline-6- sulphonic acid (ABTS) radical scavenging assay}

A 2,2-Azino-bis-(3-ethylbenzothiazoline-6sulfonic acid) (ABTS) assay was used to determine the radical scavenging activity of rhododendron extract according to the method of $\mathrm{Ng} \&$ Rosman (2019). ABTS reagent solution was freshly prepared by mixing $7 \mathrm{~mm}$ ABTS solution with $2.45 \mathrm{~mm}$ potassium persulfate. ABTS and potassium persulfate powders were separately dissolved in water to the targeted concentrations and then mixed at a ratio of $2: 1(\mathrm{v} / \mathrm{v})$. After $16 \mathrm{hr}$ incubation in the dark at room temperature, the ABTS reagent solution was diluted with ethanol until the absorbance reading reached $0.70+0.02$ at $734 \mathrm{~nm}$. A volume of $20 \mu \mathrm{L}$ of samples and standards (ascorbic acid, $\alpha$-tocopherol, and butylated hydroxytoluene (BHT)) at different concentrations was mixed with $2 \mathrm{~mL}$ of ABTS reagent. The absorbance was read at $734 \mathrm{~nm}$, and the ABTS radical scavenging activity percentage was calculated as follows:

$\%$ ABTS radical scavenging activity $=\frac{\mathrm{A}_{0}-\mathrm{A}_{1}}{\mathrm{~A}_{0}} \times 100$

Where $A_{0}$ is the absorbance of the blank and $A_{1}$ is the absorbance of the sample.

Analysis of rhododendron extracts using HPLCDAD

The analysis was performed using an HPLC (Agilent 1260 Infinity II LC System, Agilent
Technologies, USA) equipped with a diode array detector (DAD). Separation was performed on a TSKgel Super ODS column $(4.6 \times 100 \mathrm{~mm})$ (Tosoh Bioscience, Japan) at a controlled temperature of $30^{\circ} \mathrm{C}$. Binary mobile phases consisted of distilled water with $0.5 \%$ formic acid (A) and acetonitrile with $0.5 \%$ formic acid (B). Gradient condition started with solvent B from $5-40 \%$ at $0-17$ min and then decreased to $5 \%$ solvent $\mathrm{B}$ until 20 min with a flow rate of $1 \mathrm{~mL} / \mathrm{min}$. DAD was set at 350 and $520 \mathrm{~nm}$. The sample injection volume was $10 \mu \mathrm{L}$. Standard calibrations of chlorogenic acid, rutin (quercetin-3-O-rutinoside), and quercetin (quercetin3 -rhamnoside) at concentrations ranging from $0-1$ $\mathrm{mg} / \mathrm{mL}$ were used for quantification. Integration of standard and samples was performed using OpenLAB CDS ChemStation Edition software, version C.01.07 (Agilent Technologies, USA). Statistical analysis was conducted using IBM SPSS Statistics software version 20.0 (IBM, USA). Values were expressed as means \pm standard deviation (SD). Significant differences in average phytochemical content were indicated as different superscripts $(p<0.05)$.

\section{In vitro biological activity of rhododendron extract}

\section{Cell cultures}

B16F10 melanoma and RAW264.7 macrophage cells were supplied by the American Type Culture Collection (ATCC) (Manassas, VA, USA). All Gibco ${ }^{\circledR}$ Invitrogen cell culture products were purchased from the Gibthai Company, Ltd. (Bangkok, Thailand). The murine B16F10 melanoma cell line was used to determine cell viability and anti-melanogenic activity. RAW264.7 macrophages were used for antiinflammatory assays. B16F10 cells and RAW264.7 cells were cultured in a T-75 flask containing Dulbecco's Modified Eagle's Medium (DMEM) supplemented with $10 \%$ fetal bovine serum and $1 \%$ penicillin-streptomycin and maintained in a humidified atmosphere with $5 \% \mathrm{CO}_{2}$ at $37^{\circ} \mathrm{C}$. The DMEM was changed every 2 days. B16F10 cells were trypsinized at $80-85 \%$ confluence using the trypsinEDTA solution, and RAW264.7 cells were harvested with a cell scraper. Cell suspensions were used for further analysis.

\section{Cell viability}

Cell viability was determined using 3-(4,5dimethylthiazol-2yl)-2,5-diphenyltetrazolium bromide (MTT) and CellTiter-Blue ${ }^{\circledR}$. For the MTT assay, B16F10 cells were seeded at $2 \times 10^{4}$ cells/well in 96well plates. After $24 \mathrm{hr}$, three types of rhododendron extracts (FF, DF, and DL) prepared at concentrations ranging from $25-1,000 \mu \mathrm{g} / \mathrm{mL}$ were added to each well, and the plates were incubated for $24 \mathrm{hr}$ in a humidified atmosphere at $37^{\circ} \mathrm{C}$ with $5 \% \mathrm{CO}_{2}$. A 
volume of $10 \mu \mathrm{L}$ MTT solution at $5 \mathrm{mg} / \mathrm{mL}$ concentration was added to each well and incubated for $4 \mathrm{hr}$ at $37^{\circ} \mathrm{C}$. The supernatants were then aspirated, and the formazan crystals in each well were dissolved in $100 \mu \mathrm{L}$ dimethyl sulfoxide (DMSO). The absorbance was read at $570 \mathrm{~nm}$ on a microplate reader. For CellTiter-Blue ${ }^{\circledR}$, cells were seeded and treated with rhododendron extract under the conditions described previously. Then, $20 \mu \mathrm{L}$ of CellTiter-Blue ${ }^{\circledR}$ reagent was added to each well and incubated at $37^{\circ} \mathrm{C}$ under $5 \% \mathrm{CO}_{2}$ atmosphere for 1 $\mathrm{hr}$ before recording the fluorescence at $560 \mathrm{~nm}$ excitation wavelength and $590 \mathrm{~nm}$ emission wavelength using a microplate reader (Infinite M200 PRO Tecan, Männedorf, Switzerland). Cell viability was calculated using the following equation:

$$
\% \text { Cell viability }=\left(\frac{A_{\text {sample }}}{A_{\text {control }}}\right) \times 100
$$

Where $\mathrm{A}_{\text {sample }}$ is the sample absorbance and $\mathrm{A}_{\text {control }}$ is the control sample absorbance.

\section{Anti-melanogenic assay}

The anti-melanogenic assay was deduced from the melanin content in melanoma cells according to the method of Zhou et al. (2012) B16F10 cells were seeded $\left(2 \times 10^{5}\right.$ cells/well $)$ in 96 -well plates and incubated for $24 \mathrm{hr}$. Then, cells were incubated with different concentrations $(0-250 \mu \mathrm{g} / \mathrm{mL})$ of rhododendron extract for $48 \mathrm{hr}$. After treatment, the cells were washed twice with $10 \mathrm{~mm}$ PBS and mixed with $20 \mu \mathrm{L}$ of $0.25 \%$ trypsin. After $5 \mathrm{~min}$ incubation, cell culture was transferred to $1.5 \mathrm{~mL}$ Eppendorf tubes and centrifuged at 8000 r.p.m. (FA-45-30-11 rotor, model 5810R centrifuge Eppendorf Co., Bangkok, Thailand) for $5 \mathrm{~min}$. The cell pellets were dissolved with $10 \mu \mathrm{L}$ of $1 \mathrm{~m}$ sodium hydroxide $(\mathrm{NaOH})$ and incubated at $60^{\circ} \mathrm{C}$ for $1 \mathrm{hr}$. Melanin content was determined by measuring the absorbance at $405 \mathrm{~nm}$ using a microplate reader (Infinite M200 PRO Tecan, Männedorf, Switzerland) and compared with the control untreated cells.

\section{Anti-inflammatory test}

The anti-inflammatory activity of the extract was determined from the efficiency of inhibition of nitric oxide (NO) production in the cells. RAW264.7 cells were seeded in 96-well plates $\left(2 \times 10^{5}\right.$ cells/well $)$ for $24 \mathrm{hr}$, followed by treatment with $100 \mu \mathrm{L}$ of Rhododendron extract $(25-1000 \mu \mathrm{g} / \mathrm{mL})$ for $1 \mathrm{hr}$, and then stimulated or not stimulated with lipopolysaccharide (LPS) for $24 \mathrm{hr}$. One hundred microliters of culture supernatant were then collected in another plate and mixed with $100 \mathrm{iL}$ of Griess reagent. After 10-15 min, the absorbance at $540 \mathrm{~nm}$ was read and sodium nitrite $\left(\mathrm{NaNO}_{2}\right)$ was used to generate the nitrite standard curve for $\mathrm{NO}$ quantification. The remaining cells in the plate were mixed with $10 \mu \mathrm{L}$ of MTT $(5 \mathrm{mg} / \mathrm{mL})$ and incubated for $4 \mathrm{hr}$ at $37^{\circ} \mathrm{C}$ under $5 \% \mathrm{CO}_{2}$ atmosphere. The supernatants were then aspirated, and the formazan crystals in each well were dissolved in $100 \mu \mathrm{L}$ of DMSO. The absorbance was read at $570 \mathrm{~nm}$ using a microplate reader and compared with Indomethacin as the positive control. The percentage of NO production inhibition was calculated as follows:

$$
\% \text { Inhibition }=\frac{\left(\mathrm{Abs}_{\mathrm{control}}-\mathrm{Abs}_{\text {sample }}\right)}{\mathrm{Abs}_{\mathrm{control}}} \times 100
$$

Where $\mathrm{Abs}_{\text {control }}$ is the control absorbance and $\mathrm{Abs}_{\text {sample }}$ is the sample absorbance.

\section{Statistical analysis}

All data were expressed as mean \pm standard deviation (SD) (triplicate, except for cell viability assays that were conducted in quadruplicate). The differences between average values of each experimental result were evaluated by one-way analysis of variance (ANOVA) with Duncan's multiple range post hoc test. Statistical significance was set at a $p$-value less than 0.05 and presented as different superscripts. All statistical analyses were carried out using IBM SPSS Statistics version 20.0 (SPSS Inc., Chicago, IL USA).

Correlations between TPC, TFC, and antioxidant activity ( $\mathrm{IC}_{50}$ values) of Rhododendron extract were performed using Microsoft Excel, with data presented as mean \pm standard error for triplicate determinations.

\section{RESULTS}

\section{Extraction yield and phytochemical constituents}

Extraction yields of different plant parts of $R$. arboreum with $60 \%$ ethanol are shown in Table 1. The highest yield was obtained from FF (19.22\%), while DF and DL had lower extraction yields, at $16.76 \%$ and $8.50 \%$, respectively.

From preliminary phytochemical screening, saponins and tannins were the two most common compounds observed in flower and leaf samples, while terpenoids were detected only in leaves and anthraquinones were found only in flowers (Table 1).

\section{Total phenolic and flavonoid content}

Total phenolic content (TPC) of $R$. arboreum flower petals and leaf extracts using Folin-Ciocalteu reagent was expressed as gallic acid equivalent (standard curve equation: $\mathrm{y}=0.0047 \mathrm{x}+0.0172$, $\left.\mathrm{R}^{2}=0.9996\right)$. The TPC values were expressed as milligrams of GAE/g of dry extract weight (Table 2). TPC values were $121.32 \pm 0.54 \mathrm{mg} \mathrm{GAE} / \mathrm{g}$ of dry 
Table 1. Extraction yield and phytochemical components of Rhododendron arboreum ethanolic extracts

\begin{tabular}{|c|c|c|c|c|c|c|c|c|}
\hline \multirow[t]{2}{*}{ Plant part } & \multirow[t]{2}{*}{$\%$ Yield* } & \multicolumn{7}{|c|}{ Phytochemical constituent* } \\
\hline & & Alkaloids & Flavonoids & Anthraquinones & Saponins & $\begin{array}{l}\text { Cardiac } \\
\text { glycosides }\end{array}$ & Tannins & Terpenoids \\
\hline $\begin{array}{l}\text { Fresh flower } \\
\text { petals (FF) }\end{array}$ & $\begin{array}{c}19.22 \pm \\
0.05\end{array}$ & - & - & + & + & - & + & - \\
\hline $\begin{array}{l}\text { Dried flower } \\
\text { petals (DF) }\end{array}$ & $\begin{array}{c}16.76 \pm \\
0.01\end{array}$ & - & - & + & + & + & + & - \\
\hline $\begin{array}{l}\text { Dried leaves } \\
\text { (DL) }\end{array}$ & $\begin{array}{l}8.50 \pm \\
0.03\end{array}$ & - & - & - & + & - & + & + \\
\hline
\end{tabular}

* Mean values of three replications \pm standard deviation are presented. ${ }^{* *}$ present + , absent -

Table 2. Total flavonoids and total phenolic content of Rhododendron arboreum ethanolic extracts

\begin{tabular}{lcc}
\hline Plant part & TPC $(\mathrm{mg} \mathrm{GAE} / \mathrm{g} \mathrm{DE})^{\#}$ & TFC $(\mathrm{mg} \mathrm{CE} / \mathrm{g} \mathrm{DE})^{\#}$ \\
\hline Fresh flower petals (FF) & $121.32 \pm 0.54^{\mathrm{c}}$ & $51.81 \pm 0.10^{\mathrm{c}}$ \\
Dried flower petals (DF) & $167.44 \pm 0.89^{\mathrm{b}}$ & $59.01 \pm 0.28^{\mathrm{b}}$ \\
Dried leaves (DL) & $405.21 \pm 2.11^{\mathrm{a}}$ & $127.30 \pm 1.45^{\mathrm{a}}$ \\
\hline
\end{tabular}

\# Data are the average of three replications \pm standard deviation and are expressed as gallic acid equivalent per gram of dry extract.

\#車 Data are the average of three replications \pm standard deviation and are expressed as catechin equivalent per gram of dry extract.

Values within the same column followed by different superscripts are significantly different at $p<0.05$.

extract for FF and $167.44 \pm 0.89 \mathrm{mg} \mathrm{GAE} / \mathrm{g}$ dry extract for DF, while the TPC of DL was $405.21 \pm 2.11 \mathrm{mg}$ GAE/g of dry extract.

Total flavonoid content (TFC) of $R$. arboreum extracts was determined using the spectrophotometric method with aluminum chloride. The TFC values were calculated from the regression equation of the calibration curve $\left(y=0.0027 x ; R^{2}=\right.$ 0.9961 ) and expressed as mg catechin equivalent (CE) per gram of dry extract, as shown in Table 2. The TFC of FF and DF extracts were similar (51.81 \pm 0.10 and $59.01 \pm 0.28 \mathrm{mg} \mathrm{CE} / \mathrm{g}$ dry extract, respectively). Following the same trend as TPC, the TFC value of DL $(127.30 \pm 1.45 \mathrm{mg} \mathrm{CE} / \mathrm{g}$ dry extract) was two times higher than the values obtained from FF and DF samples.

\section{Antioxidant activity}

The antioxidant activity determination of all samples was conducted by assessing the free radical scavenging ability using two stable radicals for ABTS radical (ABTS) and DPPH radical (DPPH) assay. Radical scavenging activities are represented by inhibitory concentration $50\left(\mathrm{IC}_{50}\right)$. Ascorbic acid $(10.75 \pm 0.42 \mu \mathrm{g} / \mathrm{mL})$ was used as the positive control for the DPPH assay, while for ABTS assay, $\alpha$-tocopherol $(6.12 \pm 0.07 \mu \mathrm{g} / \mathrm{mL})$, butylated hydroxytoluene (BHT) $(5.55 \pm 0.03 \mu \mathrm{g} / \mathrm{mL})$, and ascorbic acid $(2.32 \pm 0.01 \mu \mathrm{g} / \mathrm{mL})$ were used as positive controls. The $\mathrm{IC}_{50}$ values of the samples were calculated from the percentage inhibitions at various concentrations (Table 3 ).

For the DPPH assay, the results indicated higher antioxidant activity of DL $\left(\mathrm{IC}_{50}=24.65 \pm 1.47 \mu \mathrm{g} / \mathrm{mL}\right)$ than DF and FF (42.34 \pm 1.13 and $48.15 \pm 1.65$ $\mu \mathrm{g} / \mathrm{mL}$, respectively), as seen from the $50 \%$ lower $\mathrm{IC}_{50}$ value. The antioxidant power determined using the ABTS assay gave the DL extract lower antioxidant activity $\left(\mathrm{IC}_{50}=76.36 \pm 2.14 \mu \mathrm{g} / \mathrm{mL}\right)$ compared to DF $(65.19 \pm 0.81 \mu \mathrm{g} / \mathrm{mL})$ and $\mathrm{FF}$ $(69.73 \pm 1.24 \mu \mathrm{g} / \mathrm{mL})$.

\section{Correlation between TPC, TFC, and antioxidant activity}

Correlations between antioxidant activity obtained from the DPPH and ABTS assays were determined by plotting the $\mathrm{IC}_{50}(\mu \mathrm{g} / \mathrm{mL})$ values of all extracts against TPC and TFC, as presented in Figure 1. Both TPC and TFC showed positive relationships with the two antioxidant activity measurements. Coefficients of determination for the DPPH method and TPC and TFC were $\mathrm{R}^{2}=0.9784$ and 0.9638 , respectively (Figure 1a). Correlation coefficients for the ABTS assay were 0.6551 and 0.7042 (for TPC and TFC, respectively), as shown in Figure $1 b$. 
Table 3. DPPH and ABTS scavenging activity of Rhododendron arboreum ethanolic extracts and standards

\begin{tabular}{lcc}
\hline Sample & $\mathrm{IC}_{50} \mathrm{DPPH}(\mu \mathrm{g} / \mathrm{mL})$ & $\mathrm{IC}_{50}$ ABTS $(\mu \mathrm{g} / \mathrm{mL})$ \\
\hline Fresh flower petals (FF) & $48.15 \pm 1.65^{\mathrm{d}}$ & $69.73 \pm 1.24^{\mathrm{d}}$ \\
Dried flower petals (DF) & $42.34 \pm 1.13^{\mathrm{c}}$ & $65.19 \pm 0.81^{\mathrm{c}}$ \\
Dried leaves (DL) & $24.65 \pm 1.47^{\mathrm{b}}$ & $76.36 \pm 2.14^{\mathrm{e}}$ \\
Ascorbic acid & $10.75 \pm 0.42^{\mathrm{a}}$ & $2.32 \pm 0.01^{\mathrm{a}}$ \\
Butylated hydroxytoluene (BHT) & - & $5.55 \pm 0.03^{\mathrm{b}}$ \\
$\alpha$-Tocopherol & - & $6.12 \pm 0.07^{\mathrm{b}}$ \\
\hline
\end{tabular}

Mean values of three replications \pm standard deviations are presented.

Different superscripts in the same column indicate the statistically significance of each value.

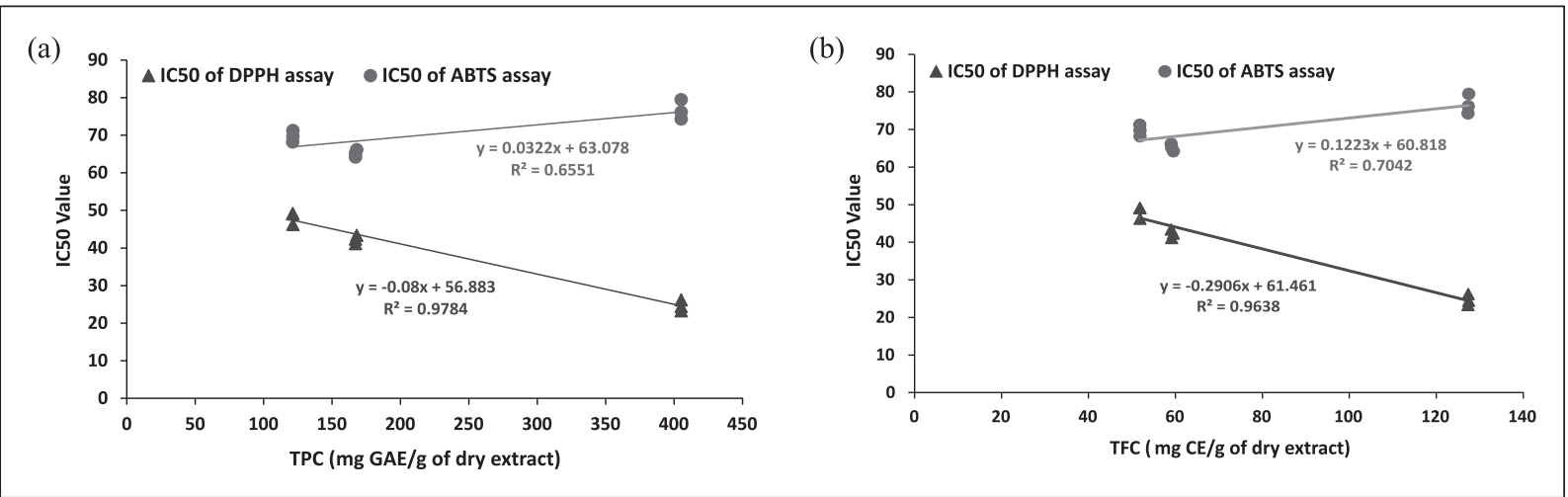

Fig. 1. Correlation between $\mathrm{IC}_{50}$ values obtained from DPPH and ABTS assays, (a) TPC and (b) TFC.

\section{HPLC-DAD Analysis}

Rhododendron plants are rich in phenolic compounds such as 5-hydroxy-6,7-dimethoxyflavone, kaempferol, quercetin, isorhamnetin, myricetin, quercitrin, rutin, taxifolin, catechin derivatives, phloretin, cyanidin, delphinidin, chlorogenic acid, coumaric acid, and caffeic acid (Rapinski et al., 2014). This indicates a wide range of phenolic constituent groups including phenolic acid, flavonoid aglycone, flavonoid derivatives, and anthocyanins. The biomarker compounds of rhododendron leaf and flowers (Swaroop et al., 2005; Sonar et al., 2012; Kumar et al., 2019; Madhvi et al., 2019), such as rutin, quercitrin, and chlorogenic acid, were quantitatively determined. These compounds have been reported to have the bioactive potential for application in cosmetic products, focusing on their antiinflammatory and anti-melanogenic properties.

The HPLC-DAD chromatograms of the FF, DF, and DL extracts are shown in Figure 2, with peak 1 representing quercetin, peak 2 rutin, and peak 3 quercitrin. Peak area calibration curves were used for quantitative analysis. Detection was performed, focusing on the maximum absorbance wavelengths of 350 and $520 \mathrm{~nm}$. Calibration curves of the standards ranged from 0 to $1 \mu \mathrm{g} / \mathrm{mL}$ and revealed good linearity with R-squared values $\geq 0.9999$ for chlorogenic acid and $\geq 0.9998$ for rutin and quercitrin, respectively.

The obtained quantitative results from the HPLC analysis are shown in Table 4. All of the targeted compounds were detected using the HPLC conditions. For compounds in all extracts, rutin was dominant, ranging from $13.49 \pm 0.30$ to $4.95 \pm$ $0.05 \mu \mathrm{g} / \mathrm{mg}$ of extract, followed by quercitrin at 12.90 \pm 0.64 to $2.74 \pm 0.03 \mu \mathrm{g} / \mathrm{mg}$ of extract and chlorogenic acid at $5.52 \pm 0.23$ to $0.55 \pm 0.02 \mu \mathrm{g} / \mathrm{mg}$ extract.

\section{Effect of $\boldsymbol{R}$. arboreum extract on cell viability}

In vitro investigations of the cell viability and proliferation rates of $R$. arboreum extracts were performed using MTT and CellTiter-Blue ${ }^{\circledR}$ cell viability assays. B16F10 cells were incubated with a range of 25 to $1,000 \mu \mathrm{g} / \mathrm{mL}$ concentrations of all extracts for $24 \mathrm{hr}$ in $5 \% \mathrm{CO}_{2}$ at $37^{\circ} \mathrm{C}$ and compared with culture media as the control for both assays.

As shown in Figure 3, no significant influence was found on MTT conversion rates (Figure 3a) or CellTiter-Blue ${ }^{\circledR}$ reducing rates (Figure $3 b$ ) of B16F10 cells applied with DF, FF, and DL extracts at 25-250 $\mu \mathrm{g} / \mathrm{mL}$ concentrations. Using higher concentrations of every extract $(500-1,000 \mu \mathrm{g} / \mathrm{mL})$ showed a negative effect on treated cells (cell viability lower 


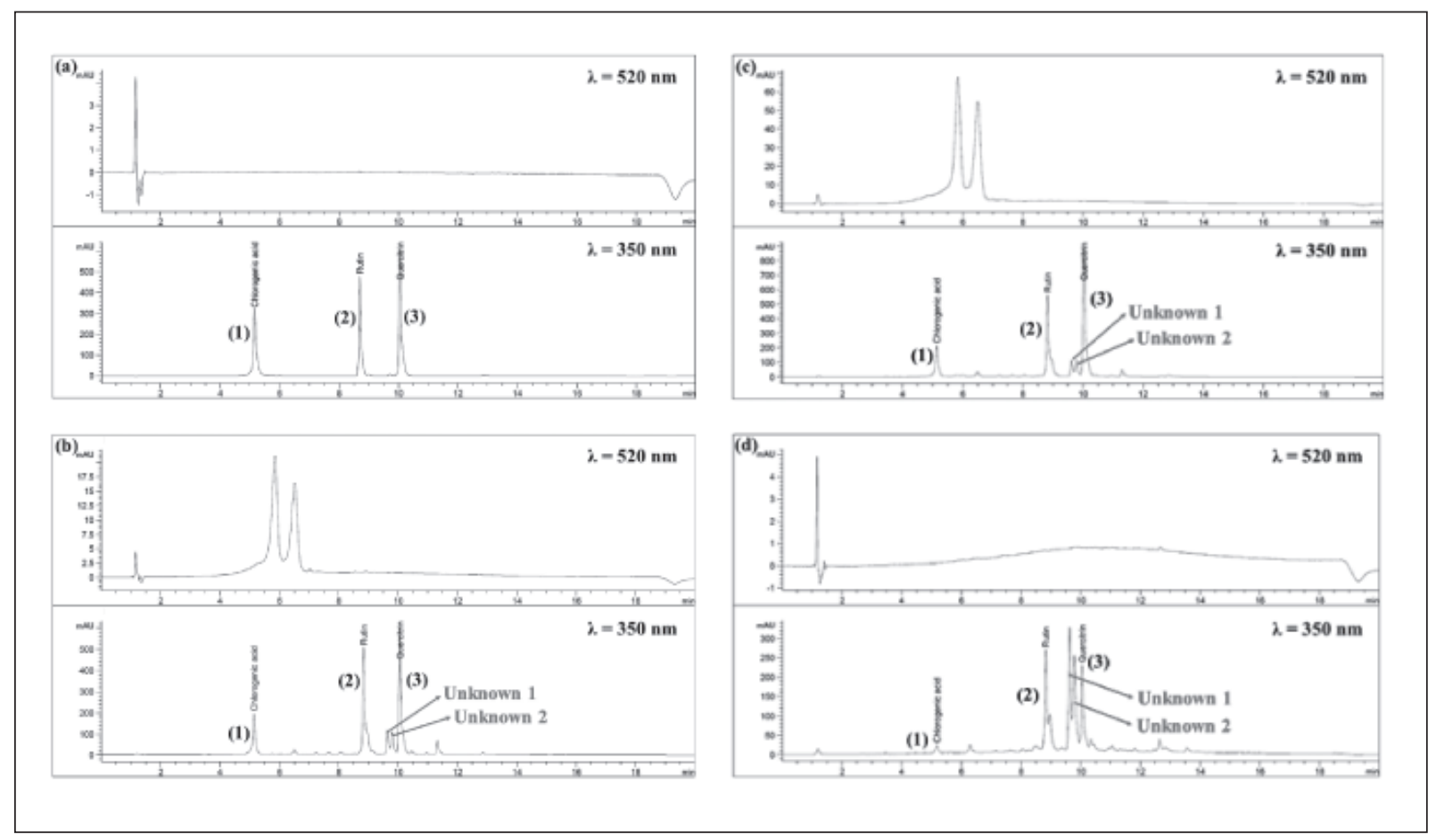

Fig. 2. HPLC chromatogram of (a) standard chlorogenic acid (1), rutin (2), and quercitrin (3) at concentrations of $2 \mu \mathrm{g} / \mathrm{mL}$, and (b), representative HPLC chromatogram of FF extract, (c) DF extract, and (d) DL extract at 350 and $520 \mathrm{~nm}$.

Table 4. Quantitative analysis of chlorogenic acid, rutin, and quercitrin in Rhododendron arboreum extracts obtained by HPLC-DAD analysis

\begin{tabular}{lccc}
\hline \multirow{2}{*}{ Extraction part } & \multicolumn{3}{c}{ Concentration $(\mu \mathrm{g} / \mathrm{mg}$ of extract) } \\
\cline { 2 - 4 } & Chlorogenic acid & Rutin & Quercitrin \\
\hline Fresh flower petals (FF) & $5.47 \pm 0.12^{\mathrm{a}}$ & $13.49 \pm 0.30^{\mathrm{a}}$ & $12.90 \pm 0.64^{\mathrm{a}}$ \\
Dried flower petals (DF) & $5.52 \pm 0.23^{\mathrm{a}}$ & $12.79 \pm 0.43^{\mathrm{a}}$ & $9.14 \pm 0.16^{\mathrm{b}}$ \\
Dried leaves (DL) & $0.55 \pm 0.02^{\mathrm{b}}$ & $4.95 \pm 0.05^{\mathrm{b}}$ & $2.74 \pm 0.03^{\mathrm{c}}$ \\
\hline
\end{tabular}

Data are the average of three replications \pm standard deviation.

Different superscripts in the same columns mean statistically significant differences of each extract.

than $80 \%$ ) compared with cells that were not treated or controls from both assays. However, at a concentration of $500 \mu \mathrm{g} / \mathrm{mL}$ of FF and DF extract, both the MTT and CellTiter-Blue ${ }^{\circledR}$ assays were non-cytotoxic to $\mathrm{B} 16 \mathrm{~F} 0$ cells. Therefore, the concentration range of 50 to $250 \mu \mathrm{g} / \mathrm{mL}$ was selected for future in vitro experiments.

\section{Anti-melanogenic activity}

In this study, non-cytotoxic concentrations (50, 100 , and $250 \mu \mathrm{g} / \mathrm{mL}$ ) of $R$. arboreum extract were selected for melanin content investigation. Results showed that the melanin content in FF, DF, and DL extract-treated cells was less than that in the control group (Figure 4). All extracts effectively decreased the melanin content in B16F10 melanoma cells in a dose-dependent manner at $50-250 \mu \mathrm{g} / \mathrm{mL}$ for FF and
DL extract and $100-250 \mu \mathrm{g} / \mathrm{mL}$ for DF extract. The highest melanin production inhibition in the cells was found in DL extract (7.26-27.56\%), followed by FF (11.85-17.56\%) and DF (6.75-13.93\%) extract, respectively.

\section{Anti-inflammatory activity}

To obtain information on the anti-inflammatory activity of $R$. arboreum, the influence of ethanolic extract on in vitro cell physiology of mouse macrophage cell line RAW264.7 was investigated. As shown in Figure 5, the results revealed that all extracts (FF, DF, and DL) dose-dependently inhibited LPSinduced $\mathrm{NO}$ production at every tested concentration $(50-250 \mu \mathrm{g} / \mathrm{mL})$. Decreasing levels of NO in LPSinduced cells treated with either leaf or flower extract were recorded compared to the positive control 


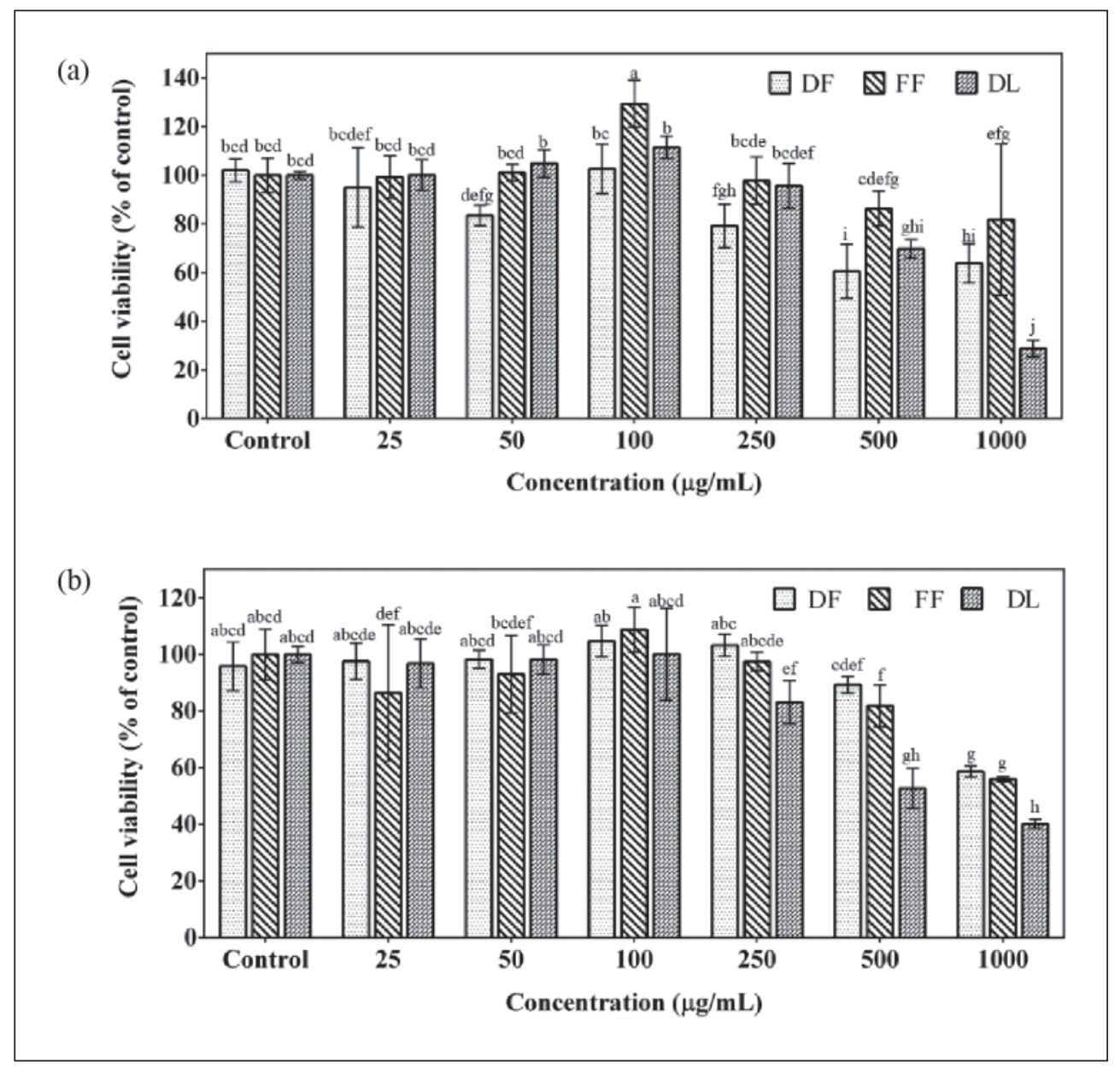

Fig. 3. Effects of Rhododendron arboreum extracts (DF, FF, and DL) on the viability of B16F10 cells incubated at $25-1,000 \mu \mathrm{g} / \mathrm{mL}$ in (a) MTT, and (b) CellTiter-Blue ${ }^{\circledR}$ cell viability assays.

Data are the average of three replications \pm standard deviation.

Different superscripts indicate significant differences in each value.

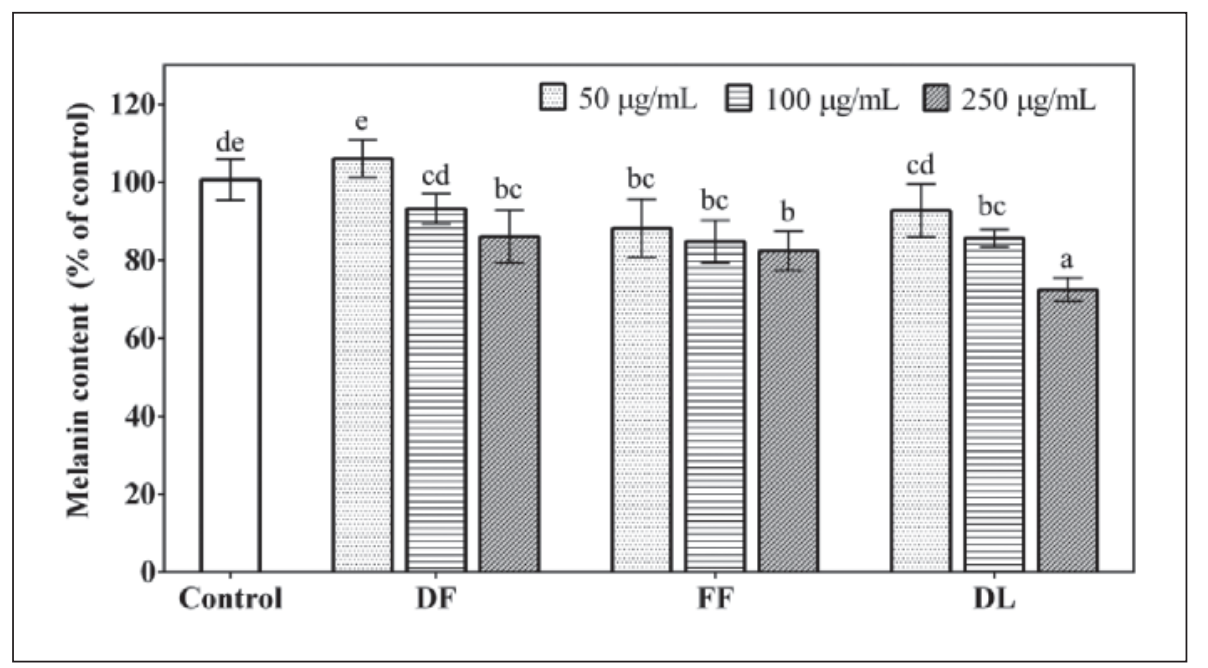

Fig. 4. Effect of Rhododendron arboreum extracts on melanin content in B6F10 melanoma cells incubated with various extract concentrations for $24 \mathrm{hr}$.

Data are the average of three replications \pm standard deviation.

Different superscripts indicate significant differences in each value. 


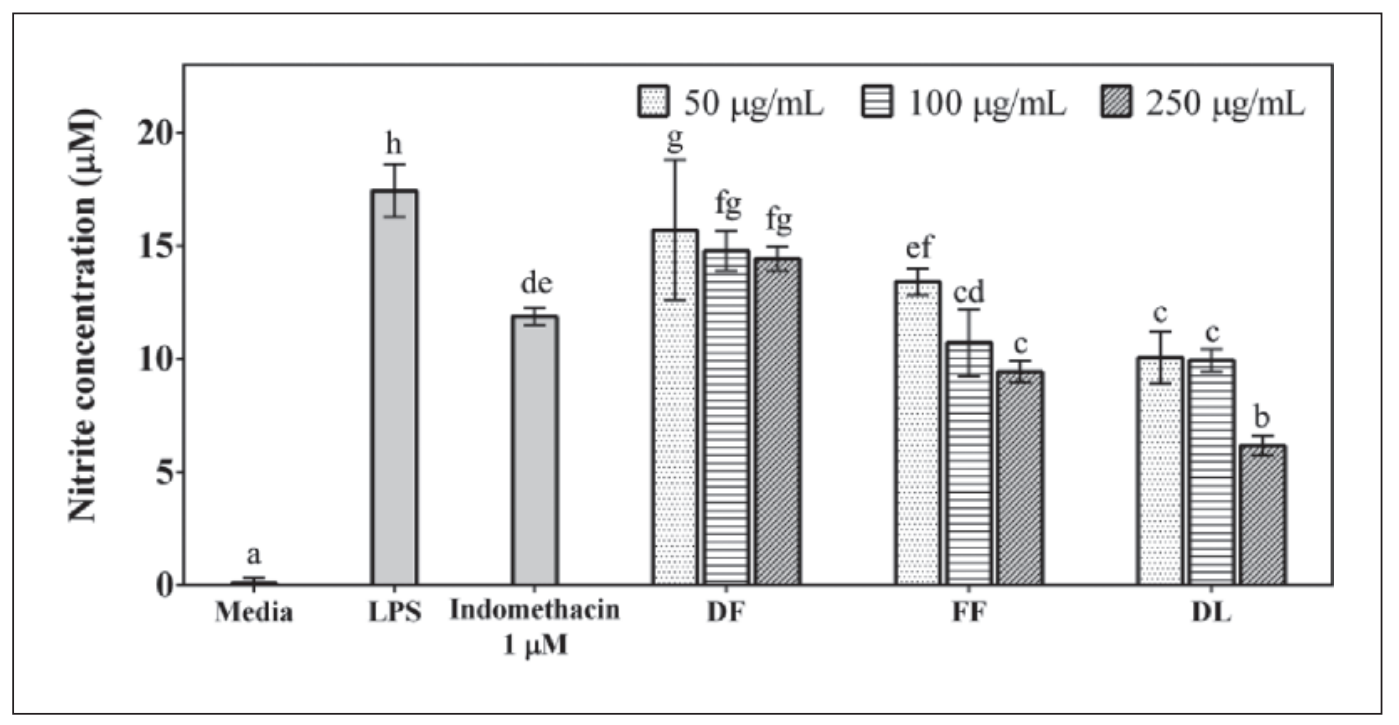

Fig. 5. Effect of Rhododendron arboreum extracts on nitric oxide production in lipopolysaccharide (LPS)activated RAW264.7 cells.

Data are the average of three replications \pm standard deviation.

Different superscripts indicate significant differences in each value.

untreated LPS-induced cells. Among the three extracts, DL showed the highest NO inhibition (up to $10.06 \pm 0.87,9.94 \pm 0.45$, and $6.17 \pm 0.41 \mu \mathrm{m}$ ), followed by FF $(13.40 \pm 0.45,10.71 \pm 1.65$, and $9.43 \pm$ $0.10 \mu \mathrm{m})$, and DF $(17.06 \pm 3.79,14.77 \pm 0.17$, and 14.64 $\pm 0.38 \mu \mathrm{m})$.

\section{DISCUSSION}

Rhododendron arboreum Sm. contains a large number of phytoconstituents, including glycosides, alkaloids, fatty acids, resins, proteins, tannins, phenolics, flavonoids, saponins, and carbohydrates (Sharma et al., 2009). These compounds are known to exert antioxidant and antimicrobial effects, which are the most powerful biological activities in rhododendron plants (Sharma et al., 2009; Rafi et al., 2018). Extracts of $R$. arboreum in Thailand have not been previously examined for their biochemical composition and bioactivity. The yield of the extracts was either higher than or comparable to that found in previous works (Nisar et al., 2011; Sonar et al., 2012; Bhandari \& Rajbhandari, 2014; Sharma et al., 2020) while different extraction yields among the same plant parts were observed. Higher extraction yield of FF than DF suggested that the higher water concentration in the FF tissue was more effective for extraction and enhanced yield. Differences in extraction yield, biochemical component profiles, and bioactivity were also observed (Sultana et al., 2009; Do et al., 2014).

Phenolic compounds are one of the largest and most important groups of plant secondary metabolites
(Singh et al., 2007). Differences in the TPC and TFC values of the three $R$. arboreum extracts were observed. Plant parts are known to contain diverse amounts of primary and secondary metabolites (Achakzai et al., 2009; Sembiring et al., 2017). Our data differed from that of previous studies owing to several factors, including plant origins, environmental factors (growth area, temperature, rainfall, and daylight), extraction method, and extraction solvents, which can alter the content of phenolic compounds and other secondary metabolites (Aryal et al., 2019). However, similar results were reported by Lubhan (2016), who recorded higher TPC and TFC values of $R$. arboreum ethanolic extracts for leaves than for flowers, at TPC $339.24 \pm 2.41 \mathrm{mg} \mathrm{GAE} / \mathrm{g}$ extract for leaves and $259.86 \pm 3.05 \mathrm{mg} \mathrm{GAE} / \mathrm{g}$ extract for flowers and TFC $17.90 \pm 0.62 \mathrm{mg} \mathrm{QE} / \mathrm{g}$ and $15.17 \pm 0.56 \mathrm{mg} \mathrm{QE} / \mathrm{g}$ for leaves and flowers, respectively. Similar findings using different extraction methods and solvents were reported by Bhandari and Rajbhandari (2014). They found that the TPC value of $R$. arboreum leaf methanolic extract, at $495.0 \pm 8.66 \mathrm{mg} \mathrm{GAE} / \mathrm{g}$ extract, was slightly higher than that of the flowers and petals, at $440.0 \pm 0.00$ and $485.0 \pm 5.00 \mathrm{mg} \mathrm{GAE} / \mathrm{g}$ extract, respectively. Similar to that of TPC, the TFC of leaf extract was slightly higher than that in flower and petal samples $(150.0 \pm 0.00,103.8 \pm 2.16$, and 126.8 $\pm 3.24 \mathrm{mg} \mathrm{QE} / \mathrm{g}$ extract for leaves, flowers, and petals, respectively).

Antioxidant activity is one of the most significant biological properties of rhododendron species (Rafi et al., 2018). Several studies have reported powerful antioxidant properties both in vitro 
and in vivo (Srivastava, 2012; Rafi et al., 2018; Madhvi et al., 2019). Here, two in vitro antioxidant power assays were performed on the ABTS radical and $\mathrm{DPPH}$ radical. The low $\mathrm{IC}_{50}$ values indicated high antioxidant activity. The inhibition percentage obtained from the two methods showed that all extracts had antioxidant activity; however, in two of the experiments, all extract samples had lower antioxidant capacity compared to the standards. Interestingly, diverse antioxidant activity assays of the same sample yielded significantly different results because of the disparate compounds responsible for the antioxidant power and conditions of the test. The two methods used in this study are usually classified as single electron transfer (SET) reaction assays (Prior et al., 2005). They showed typical selectivity as well as advantages and disadvantages in the measurement of antioxidant power resulting from the different antioxidant capacities of the samples. The DPPH assay is usually dissolved in organic media, whereas the ABTS assay is dependent on the generation of a blue/green ABTS+, which is soluble in both aqueous and organic solvents. Therefore, the DPPH assay represents the antioxidant potential of more lipophilic compounds, while the ABTS assay represents both hydrophilic and lipophilic compounds $(\mathrm{Ng} \&$ See, 2019). Synergism or antagonism renders antioxidant activity dependent on concentration, structure, and interaction among the antioxidants in the mixture (Đordevic et al., 2011). Further investigations are required to purify and identify each potential antioxidant component in rhododendron extract.

A high correlation between phenolic and flavonoid content and antioxidant power of the rhododendron genus has been confirmed by several researchers (Srivastava, 2012; Bhandari \& Rajbhandari, 2014; Lin et al., 2014; Rafi et al., 2018). A previous analysis showed that correlation coefficient values were close to one, indicating that antioxidant activities in rhododendron plant extracts emanated from both phenolics and flavonoids (Aryal et al., 2019). Correlation between the DPPH method and TPC and TFC was higher than for the ABTS method, possibly due to various kinds of antioxidants present in the samples that reacted differently with the radicals. Furthermore, synergistic or antagonistic interactions between different antioxidant phytoconstituents are another possibility, as mentioned earlier.

The detection of quercitrin, rutin, and chlorogenic acid in $R$. arboreum extracts using chromatographic and electrophoretic methods has been previously reported (Gautam et al., 2016). Here, HPLC was selected owing to its sensitivity, precision, and specificity. The quantities of each compound varied with statistical significance among $R$. arboreum plant parts, but their ranking was similar. The most abundant compound of all extracts was rutin, followed by quercitrin and chlorogenic acid, respectively. When comparing the results between $R$. arboreum extracts obtained from the same plant part, differences were found among fresh (FF) and dried flower (DF) extracts, indicating the effect of heat on quercitrin content but not on rutin and chlorogenic acid content. The DL extract presented the lowest quantity of the three compounds, with higher peak areas of two unidentified compounds in the HPLC chromatogram, which contributed to lower quantities of the interested components in lead extract (DL) than in flower extracts (FF and DF). Two unknown compounds require further identification. Moreover, this result suggests that flower extracts are richer in the targeted compounds and thus more suitable for further applications in related healthcare products.

The in vitro toxicity of rhododendron genus extracts has been reported in both animal and human cell lines, including the mouse epithelial cell line, human keratinocyte cells, and cancerous cells (Srivastava, 2012; Madhvi et al., 2019). In this study, treating cells with low concentrations (lower than 500 $\mu \mathrm{g} / \mathrm{mL}$ ) of the extracts yielded mild or non-toxic effects, but a remarkable effect was observed at higher concentrations, similar to that of previous works (Gescher et al., 2011; Nisarshy et al., 2013; Rezk et al., 2015). Different cell types may exhibit differential activity toward specific compounds or plant extracts. Interestingly, in our experiment, treatments at $100 \mu \mathrm{g} / \mathrm{mL}$ of FF, DF, and DL extracts of both MTT and CellTiter-Blue ${ }^{\circledR}$ cell viability assays revealed the highest cell proliferation compared to other concentrations. This highlighted their potential non-cytotoxic concentration for cell treatment in future applications.

The anti-inflammatory activity of $R$. arboreum extract under in vitro conditions (Cao et al., 2004; Rawat et al., 2017) could be due to the presence of phytochemicals (flavonoids [hyperin], tannins, saponins, etc.) that have medicinal anti-inflammatory and anti-nociceptive properties (Nisarshy et al., 2013; Rafi et al., 2018). All extracts were noncytotoxic to macrophage cells at test concentrations of $50-250 \mu \mathrm{g} / \mathrm{mL}$ that confirmed by the MTT assay. The results indicated that the NO synthesis inhibition by extracts was not due to cytotoxic effects. Therefore, this plant has the potential for antiinflammatory applications.

Melanin is a pigment that gives rise to the color of skin, and its accumulation plays a significant role in abnormal skin pigmentation disorders. In the cosmetics industry, melanin content in human skin plays a negative role and reduces skin whitening effects. As a result, new compounds to reduce the 
melanin content in human skin are in demand. The inhibitory effect of $R$. arboreum Sm. extracts on melanin production were also investigated. Our findings suggest that $R$. arboreum extracts have potential for melanin content inhibition, concurring with previous studies (Yang et al., 2019; Young et al., 2020) that described significant dose-dependent inhibition of melanin content by Rhododendron spp. extracts. Therefore, this plant is a potential source for a novel natural whitening agent for ultraviolet (UV)-sensitive skin.

\section{CONCLUSION}

Our comprehensive study on Rhododendron arboreum $\mathrm{Sm}$. grown in mountainous areas of Northern Thailand focused on in vitro biological activities, phytochemical screening, and quantitative analysis of bioactive secondary metabolite markers selected based on their previously reported antiinflammatory and anti-melanogenesis activities. Ethanolic extracts of dried and fresh flower petals (DF and FF) and dried leaves (DL) comprised varied contents of phenolic and flavonoid compounds. These compositions were quantitatively related to the antioxidant capability of each extracted sample. Cytotoxicity investigation of DF, FF, and DL extracts demonstrated that these extracts affected B16F10 and RAW 264.7 cell viability only at high concentrations. These extract samples were effective within the non-cytotoxic concentration range to inhibit melanogenesis and LPS induced inflammation in vitro, with the DL extract more potent than DF and FF. This related with results for TPC and TFC but contrasted with the bioactive marker content determined by quantitative HPLC. Findings suggested that non-marker compounds played a role in bioactivities, individually or synergistically. Therefore, further research is required to elucidate the bio-efficacy, purification, and isolation of $R$. arboreum contained compounds. This bioactivity investigation proved that ethanolic extracts from DF, $\mathrm{FF}$, and DL of $R$. arboreum grown in Thailand have potential as raw material for cosmetic product development, especially skin whitening products. However, further detailed research is required to accurately determine the biological mechanisms.

\section{ACKNOWLEDGEMENTS}

This work was financially supported by Kasetsart University. The authors are particularly grateful to Mr. Somsit Promma and Royal Project Foundation, Chiang Mai, Thailand for kindly provided $R$. arboreum Sm. plants used in the work.

\section{REFERENCES}

Aburjai, T. \& Natsheh, F. 2003. Plants Used in Cosmetics. Phytotherapy Research, 17: 987-1000.

Achakzai, A.K.K., Palwasha, A., Ayeesha, M., Kayani, S.A. \& Tareen, R.B. 2009. Response of plant parts and age on the distribution of secondary metabolites on plants found in Quetta. Pakistan Journal of Botany, 41: 2129-2135.

Ainsworth, E.A. \& Gillespie, K.M. 2007. Estimation of total phenolic content and other oxidation substrates in plant tissues using Folin-Ciocalteu reagent. Nature Protocol, 2: 875-877.

Aryal, S., Baniya, M.K., Danekhu, K., Kunwar, P., Gurung, R. \& Koirala, N. 2019. Total phenolic content, flavonoid content and antioxidant potential of wild vegetables from Western Nepal. Plants, 8(96): 1-12.

Ayoola, G., Coker, H., Adesegun, S., Adepoju-Bello, A., Obaweya, K., Ezennia, E. \& Atangbayila, T. 2008. Phytochemical screening and antioxidant activities of some selected medicinal plants used for malaria therapy in Southwestern Nigeria. Tropical Journal of Pharmaceutical Research, 7(3): 1019-1024.

Bhandari, L. \& Rajbhandari, M. 2015. Isolation of quercetin from flower petals, estimation of total phenolic, total flavonoid and antioxidant activity of the different parts of Rhododendron arboreum smith. Scientific World, 12(12): 34-40.

Cao, Y., Chu, Q. \& Ye, J. 2004. Chromatographic and electrophoretic methods for pharmaceutically active compounds in Rhododendron dauricum. Journal of Chromatography B-Analytical Technologies in the Biomedical and Life Sciences, 812: 231-240.

Choi, M.H. \& Shin, H.J. 2016. Anti-melanogenesis effect of quercetin. Cosmetics, 3(18): 1-16.

Demir, S., Turan, I. \& Aliyazicioglu, Y. 2016. Selective cytotoxic effect of Rhododendron luteum extract on human colon and liver cancer cells. JBUON, 21(4): 883-888.

Do, Q.D., Angkawijaya, A.E., Tran-Nguyen, P.L., Huynh, L.H., Soetaredjo, F.E., Ismadji, S. \& Ju, Y.H. 2014. Effect of extraction solvent on total phenol content, total flavonoid content, and antioxidant activity of Limnophila aromatica. Journal of Food and Drug Analysis, 22: 296-302.

Dong, J., Ma, X., Wei, Q., Peng, S. \& Zhang, S. 2011. Effects of growing location on the contents of secondary metabolites in the leaves of four selected superior clones of Eucommia ulmoides. Industrial Crops and Products, 34: 1607-1614.

Đorðeviæ, T., Siler Marinkovic, S. \& DimitrijevicBrankovic, S. 2011. Antioxidant activity and total phenolic content in some cereals and legumes. International Journal of Food Properties, 14: 175-184. 
Gautam, V., Sharma, A., Arora, S. \& Bhardwaj, R. 2016. Bioactive compounds in the different extracts of flowers of Rhododendron arboreum Sm. Journal of Chemical and Pharmaceutical Research, 8(5): 439-444.

Gêgotek, A., Ambrozewicz, E., Jastrzab, A., JarockaKarpowicz, I. \& Skrzydlewska, E. 2019. Rutin and ascorbic acid cooperation in antioxidant and antiapoptotic effect on human skin keratinocytes and fibroblasts exposed to UVA and UVB radiation. Archives of Dermatological Research, 311: 203-219.

Gescher, K., Kuhn, J., Hafezi, W., Louis, A., Derksen, A., Deters, A., Lorentzen, E. \& Hensel, A. 2011. Inhibition of viral adsorption and penetration by an aqueous extract from Rhododendron ferrugineum L. as antiviral principle against herpes simplex virus type-1. Fitoterapia, 82: 408413.

Gonzalez-Minero, F. \& Bravo-Díaz, L. 2018. The use of plants in skin-care products, cosmetics and fragrances: Past and present. Cosmetics, 5(50): $1-9$.

Hong, C.O., Lee, H.A., Rhee, C.H., Choung, S.Y. \& Lee, K.W. 2013. Separation of the Antioxidant Compound Quercitrin from Lindera obtusiloba Blume and Its Antimelanogenic Effect on B16F10 Melanoma Cells. Bioscience, Biotechnology, and Biochemistry, 77: 58-64.

Joshi, L.S. \& Pawar, H.A. 2015. Herbal cosmetics and cosmeceuticals: An overview. Natural Products Chemistry \& Research, 3(2): 2-8.

Kim, M.J., Kim, S., Yun, S., Kim, S.Y., Hyun, K., Lee, J., Lee, H. \& Hyun, C.G. 2016. Melanogenesis inhibitory activity of Rhododendron Weyrichii in mouse B16 melanoma cells. Oriental Journal of Chemistry, 32: 1899-1907.

Krishna, H., Attri, B.L. \& Kumar, A. 2014. Improvised Rhododendron squash: processing effects on antioxidant composition and organoleptic attributes. Journal of Food Science and Technology, 51: 3404-3410.

Kumar, V., Suri, S., Rasane, P., Gat, Y., Sangma, C., Jakhu, H. \& Sharma, M. 2019. Bioactive compounds, health benefits and utilization of Rhododendron: A comprehensive review. Agriculture and Food Security, 8(6): 1-7.

Lin, C.Y., Lin, L.C., Ho, S.T., Tung, Y.T., Tseng, Y.H. \& Wu, J.H. 2014. Antioxidant activities and phytochemicals of leaf extracts from 10 native Rhododendron species in Taiwan. Evidence-based Complementary and Alternative Medicine, 2014: 1-9.

Liu, W., Liu, J., Yin, D. \& Zhao, X. 2015. Influence of ecological factors on the production of active substances in the anti-cancer plant Sinopodophyllum hexandrum (Royle) T.S. Ying. PLoS ONE, 10(4): e0122981.
Lubhan, S. 2016. Evaluation of Neuroprotective effect of Rhododendron arboreum Fumaria parviflora and Stephania glabra against Colchicine Induced Cognitive Dysfunction and Oxidative Damage in Mice (Ph.D.). Uttarakhand Technical University.

Madhvi, S., Sharma, M., Iqbal, J. \& Younis, M. 2019. Phytochemistry, traditional uses and pharmacology of Rhododendron arboreum: A Review. Research Journal of Pharmacy and Technology, 12(9): 4565-4574.

Mankil, J., Moonsoo, P., Hyun, C.L., Yoon-Ho, K., Eun, S.K. \& Sang, K.K. 2006. Antidiabetic agents from medicinal plants. Current Medicinal Chemistry, 13: 1203-1218.

$\mathrm{Ng}$, Z.X. \& Rosman, N.F. 2019. In vitro digestion and domestic cooking improved the total antioxidant activity and carbohydrate-digestive enzymes inhibitory potential of selected edible mushrooms. Journal of Food Science and Technology, 56(2): 865-877.

Ng, Z.X., Samsuri, S.N. \& Young, P.H. 2020. The antioxidant index and chemometric analysis of tannin, flavonoid, and total phenolic extracted from medicinal plant foods with the solvents of different polarities. Journal of Food Processing and Preservation, 44: e14680.

Ng, Z.X. \& See, A.N. 2019. Effect of in vitro digestion on the total polyphenol and flavonoid, antioxidant activity and carbohydrate hydrolyzing enzymes inhibitory potential of selected functional plant based foods. Journal of Food Processing and Preservation, 43(4): e13903.

Ng, Z.X., Young, P.H. \& Lim, S.Y. 2020. Customized dying treatments increased the extraction of phytochemicals and antioxidant activity from economically viable medicinal plants. Industrial Crop and Products, 155: 112815

Nisar, M., Ali, S. \& Qaisar, M. 2011. Preliminary phytochemical screening of flowers, leaves, bark, stem and roots of Rhododendron arboretum. Middle-East Journal of Scientific Research, 10: 472-476.

Nisarshy, M., Ali, S. \& Qaisar, M.N. 2013. Antibacterial and cytotoxic activities of the methanolic extracts of Rhododendron arboreum. Journal of Medicinal Plants Research, 7: 398403.

Painuli, S., Joshi, S., Bhardwaj, A., Meena, R.C., Misra, K., Rai, N. \& Kumar, N. 2018. In vitro antioxidant and anticancer activities of leaf extracts of Rhododendron arboreum and Rhododendron campanulatum from Uttarakhand Region of India. Pharmacognosy Magazine, 14(57): S294S303. 
Popescu, R. \& Kopp, B. 2013. The genus Rhododendron: An ethnopharmacological and toxicological review. Journal of Ethnopharmacology, 147: 42-62.

Prior, R.L., Wu, X. \& Schaich, K. 2005. Standardized Methods for the determination of antioxidant capacity and phenolics in foods and dietary supplements. Journal of Agricultural and Food Chemistry, 53: 4290-4302.

Qiang, Y., Zhou, B. \& Gao, K. 2011. Chemical constituents of plants from the genus Rhododendron. Chemistry \& Biodiversity, 8: $792-815$.

Rafi, M., Febriany, S., Wulandari, P., Suparto, I., Ridwan, T., Rahayu, S. \& Siswoyo, D.M. 2018. Total phenolics, flavonoids, and anthocyanin contents of six Vireya Rhododendron from Indonesia and evaluation of their antioxidant activities. Journal of Applied Pharmaceutical Science, 8: 49-54.

Rapinski, M., Liu, R., Saleem, A., Arnason, J.T. \& Cuerrier, A. 2014. Environmental trends in the variation of biologically active phenolic compounds in Labrador tea, Rhododendron groenlandicum, from northern Quebec, Canada. Botany, 92: 783-794.

Rawat, P., Rai, N., Kumar, N. \& Bachheti, R. 2017. Review on Rhododendron arboreum - a magical tree. Oriental Pharmacy and Experimental Medicine, 17: 1-12.

Rezk, A., Al-Hashimi, A., John, W., Schepker, H., Ullrich, M.S. \& Brix, K. 2015. Assessment of cytotoxicity exerted by leaf extracts from plants of the genus Rhododendron towards epidermal keratinocytes and intestine epithelial cells. $B M C$ Complementary and Alternative Medicine, 15: 1-18.

Santisuk, T. \& Balslev, H. 2015. Flora of Thailand. Vol. 13. Part 1. Achariaceae, Adoxaceae, Cannabaceae, Caprifoliaceae, Ericaceae, Salicaceae \& Ulmaceae. The Forest Herbarium, Department of National Parks, Wildlife and Plant Conservation, Thailand. 160 pp.

Sembiring, E., Elya, B. \& Sauriasari, R. 2017. Phytochemical screening, total flavonoid and total phenolic content and antioxidant activity of different parts of Caesalpinia bonduc (L.) Roxb. Pharmacognosy Journal, 10: 123-127.

Sharma, D., Lamichhane, J., Basnet, S., Pradhan, A., Bhandari, T., Ghimire, N. \& Pandey, S. 2020. DNA Barcoding, phytochemical screening and antimicrobial activity of Rhododendron arboreum, a high altitudinal medicinal plant from Nepal. Eurasian Journal of Forest Science, 8(2): 140-151.
Sharma, N., Sharma, U.K., Gupta, A.P. \& Sinha, A.K. 2010. Simultaneous determination of epicatechin, syringic acid, quercetin-3-O-galactoside and quercitrin in the leaves of Rhododendron species by using a validated HPTLC method. Journal of Food Composition and Analysis, 23: 214-219.

Sharma, S., Chaudhary, R., Rolta, R., Sharma, N., Sourirajan, A., Dev, K. \& Kumar, V. 2021. Effect of solvent on yield, phytochemicals and in vitro antioxidant potential of Rhododendron arboreum. Research Journal of Pharmacy and Technology, 14(1): 311-316.

Sharma, U.R., Surendra, V., Jha, S., Tigari, P., Goli, D. \& Reddy, S. 2009. Evaluation of Antinflammatory activity of Rhododendron Arboreum herb extract on experimental animal. Archives of Pharmacal Research, 1(1): 58-61.

Singh, R., Singh, S., Kumar, S. \& Arora, S. 2007. Evaluation of antioxidant potential of ethyl acetate extract/fractions of Acacia auriculiformis A. Cunn. Food and Chemical Toxicology, 45: 1216-1223.

Slavova-Kazakova, A., Janiak, M.A., Sulewska, K., Kancheva, V.D. \& Karamac, M. 2021. Synergistic, additive, and antagonistic antioxidant effects in the mixtures of curcumin with $(-)$-epicatechin and with a green tea fraction containing (-)-epicatechin. Food Chemistry, 360: 129994.

Sonar, P., Singh, R., Bansal, P., Balapure, A. \& Saraf, S. 2012. R. Arboreum flower and leaf extracts: RP-HPTLC screening, isolation, characterization and biological activity. Rasayan Journal of Chemistry, 5: 165-172.

Srivastava, P. 2012. Rhododendron arboreum: An overview. Journal of Applied Pharmaceutical Science, 02: 158-162.

Sultana, B., Anwar, F. \& Ashraf, M. 2009. Effect of extraction solvent/technique on the antioxidant activity of selected medicinal plant extracts. Molecules, 14: 2167-2180.

Swamidasan, R., Prakash, T., Divakar, G., Kamalesh, D.R., Dixit, P. \& Chandrasekar, S.B. 2008. Adaptogenic activity of ethanolic extract of leaves of Rhododendron arboretum in mice and rats. Indian Journal of Pharmacology, 40(2): 402.

Swaroop, A., Gupta, A.P. \& Sinha, A.K. 2005. Simultaneous determination of quercetin, rutin and coumaric acid in flowers of Rhododendron arboreum by HPTLC1. Chromatographia, 62: 649-652.

Thangaraj, V. 2013. Hypolipidemic effect of Rhododendron arboretum Sm. Linn flower juice in experimentally induced hypercholestermic rabbits. International Journal of Pharmaceutical and Biomedical Research, 4: 46-49. 
Tigari, P., Fadadu, S., Sharma, U.R., Surendra, V., Goli, D., Stamin, P. \& Dupadahalli, K. 2008. Hepatoprotective activity of leaves of Rhododendron arboreum in $\mathrm{CCl} 4$ induced hepatotoxicity in rats. Journal of Medicinal Plants Research, 2(11): 315-320.

Verma, N., Singh, A.P., Amresh, G., Sahu, P.K. \& Rao Ch, V. 2011. Protective effect of ethyl acetate fraction of Rhododendron arboreum flowers against carbon tetrachloride-induced hepatotoxicity in experimental models. Indian Journal of Pharmacology, 43: 291-295.

Yang, E.J., Yun, S.H., Ko, J.H., Kang, H.K., Lee, J.N., Park, S.M. \& Hyun, C.G. 2019. Protective effect of Rhododendron weyrichii flower extract against UVB-induced proinflammatory cytokine production in human keratinocytes. Journal of Applied Pharmaceutical Science, 9: 15-19.
Young, H.A.S., Young, J.J., Young, K.H., Tae-Heung, K.I.M. \& Jae-Kyung, Y. 2020. Tyrosinase activity and melanogenic effects of Rhododendron schlippenbachii extract in vivo and in vitro. Journal of the Korean Wood Science and Technology, 48(2): 166-180.

Younus, M., Hasan, M.M., Ali, S., Saddq, B., Sarwar, G., Ullah, M.I., Maqsood, A., Ahmar, S., MoraPoblete, F., Hassan, F., Chen, J.T., Noureldeen, A. \& Darwish, H. 2021. Extracts of Euphorbia nivulia Buch.-Ham. showed both phytotoxic and insecticidal capacities against Lemna minor L. and Oxycarenus hyalinipennis Costa. PLoS ONE, 16(4): e 0250118.

Zhou, J., Shang, J., Ping, F. \& Zhao, G. 2012. Alcohol extract from Vernonia anthelmintica (L.) willd seed enhances melanin synthesis through activation of the p38 MAPK signaling pathway in B16F10 cells and primary melanocytes. Journal of Ethnopharmacology, 143: 639-647. 
